\title{
Risk Determinants of Dental Caries and Oral Hygiene Status in 3-15 Year-Old Recent Immigrant and Refugee Children in Saskatchewan, Canada: A Pilot Study
}

\author{
Jay Hoover $^{1}$ (D) Hassan Vatanparast ${ }^{2} \cdot{\text { Gerry } \text { Uswak }^{1}}^{1}$
}

Published online: 27 June 2016

(C) The Author(s) 2016. This article is published with open access at Springerlink.com

\begin{abstract}
This study aimed to identify the risk determinants of caries and record oral hygiene status in recent immigrant and refugee children residing in Saskatoon and Regina, Saskatchewan, Canada. Convenience samples of 133, 3-15 year-old recent immigrant and refugee children, and 86 adult guardians were recruited. Clinical examination of children and survey of their guardians explored the presence of at least one decayed tooth in the child's mouth; and the knowledge, attitudes, behaviors, among other aspects in adult participants. Refugee children had statistically significant higher decayed, missing, filled teeth (DMFT) scores (mean dmft/DMFT score $5.80 \pm 4.24$ ) than immigrant children (mean $\mathrm{dmft} / \mathrm{DMFT}$ score $3.52 \pm 3.78(p<0.001)$. Adult immigrants had significantly higher proficiency in English language, knowledge about preventive components like fluoride and dental floss compared to refugee adults. The results of this study confirm the poorer state of oral health among refugee and immigrant children compared to Canadian children.
\end{abstract}

Keywords Oral health · New immigrants · Refugees · Saskatchewan

Jay Hoover

j.hoover@usask.ca

1 College of Dentistry, University of Saskatchewan, 105 Wiggins Road, Saskatoon, SK, Canada

2 College of Pharmacy and Nutrition, University of Saskatchewan, Saskatoon, SK, Canada

\section{Background}

Immigration has had its presence and effects on Canada for a very long time, resulting in a significant number of immigrants and refugees living in this country today $[1,2]$. Preventable oral diseases such as caries are expensive to manage, especially in Canada, affecting the economy through lost work time and school days, [3]. The pain and discomfort associated with unmet dental treatment needs could result in decreased school attendance and performance $[4,5]$.

Studies indicate that recent immigrant children and adults have higher unmet oral health needs and appear to be at a greater risk for oral and dental diseases compared to their native counterparts [5]. A Greek study reported that immigrant children had 1.68-4.34 higher odds for higher decayed, missing and filled teeth scores (DMFT values), higher unmet treatment needs and poorer oral hygiene levels than their Greek counterparts. Additionally, children from lower income areas were 1.2-2.14 times at greater risk for developing an increased caries severity and poorer oral hygiene [6]. A similar trend in oral health has been documented, primarily in Central Canada [7-12]. The reasons for this are varied and include a lack of finances and dental insurance, discrepancies in oral health knowledge, beliefs and attitudes, a lack of motivation and an underutilization of available dental service especially among low-income groups [13-15]. Over the recent years, two major cities in the province of Saskatchewan, Saskatoon, and Regina, have become home to a large number of new immigrant and refugees. However, published data on the oral health status, its risk determinants and treatment needs of this population group is scarce in Western Canada, including Saskatchewan. Such data is necessary to plan and implement relevant intervention strategies to improve the 
oral health of adults and children alike. This study was therefore undertaken to fill this crucial gap in the existing literature.

\section{Theoretical Framework}

A multitude of enabling factors such as a lack of finances and dental insurance, discrepancies in oral health knowledge, beliefs and attitudes stress, depression, low utilization of health services, and lack of motivation make recent immigrants and refugees highly susceptible to the development of oral diseases [13-15].

\section{Methods}

Convenience samples (due to budgetary and time constraints) of 133, 3-15 year-old recent immigrant and refugee children and 86 adult guardians were recruited in Saskatoon and Regina. Each participant had arrived in Canada within the last 7 years. The subjects were part of a larger study referred to as 'Healthy Immigrant Children Research' study, which assessed the general health and nutrition, socioeconomic and food security status in this sample. Informed consent was obtained from the adult guardians prior to the administration of the survey and initiation of the clinical examination. The data were collected from September 2012 to June 2013.

\section{Clinical Examination}

The clinical examinations were conducted by two experienced clinicians (one in each locale) using a portable dental unit, dental mirror and a dental explorer. The permanent, deciduous and mixed dentitions were analyzed together. The caries status was assessed in terms of the presence of the number of decayed, missing and filled teeth (dmft/ DMFT). The second molars were excluded as these teeth were fully erupted in only a few participants. Oral hygiene status (debris and calculus) was evaluated by means of the Simplified Oral Hygiene Index (OHIS) described by Green and Vermillion [16] on the following teeth: permanent maxillary right first molar, right central incisor, left the first molar, permanent mandibular left first molar, left central incisor, right first molar. Primary maxillary right central incisors, mandibular left central incisors, and first molars were assessed when applicable. The OHIS scores for each participant was calculated before comparing the scores between the two groups. Disclosing agents were not used. The absence of gingivitis upon visual inspection was recorded if the gingiva appeared to be clinically healthy and showed no signs of inflammation such as redness and swelling. The gingival status was recorded on the same teeth and surfaces used to score for debris. Probing of the soft tissues was not attempted and no radiographs were taken. Overall treatment needs for urgent treatment for pain and infection, extractions, restorations, orthodontics, plaque control instructions and scaling; root planning were also recorded.

\section{Questionnaire}

All adults accompanying the children completed a questionnaire comprising of selected questions adapted from the literature [17-20] aiming to elicit oral health knowledge and practices, perceived oral health status and perceived barriers to oral care in Saskatchewan. The survey instrument facilitated a face-to-face interview with trained interpreters. The study was conducted in full accordance with ethical principles and with the approval of the Behavioral Research Ethics Board, University of Saskatchewan, Canada. The descriptive analysis was done using SPSS 20.0 and SAS 9.3 was used to perform regression analysis. Descriptive results were presented as means and standard deviations for continuous variables. For categorical variables, the distribution of participants across variables of interest was calculated. A comparison across immigrant and refugee groups was carried out using Independent $t$ test and Mann-Whitney $\mathrm{U}$ tests, as appropriate for continuous variables and Chi square test and Fisher's exact tests, as applicable for categorical variables. The outcome of interest for logistic regression was the presence or absence of at least one carious tooth in the child's mouth. Alpha was set at the level of 0.05 in all analyses.

\section{Results}

\section{Clinical Examination}

The immigrant group consisted of 44 children/adolescents (22 females and 22 males), mean age; $8.63 \pm 2.96$ years (14.51-3.18 years); refugee group consisted of 89 participants (53 males and 36 females), mean age; $9.22 \pm 2.89$ years (range 15.17-3.18 years) (Table 1). The Oral Hygiene Index Scores (OHIS) for both the groups were comparable without any statistically significant difference; the mean OHIS scores were $1.51 \pm 0.88$ and $1.57 \pm 0.99$ for immigrant and refugee groups respectively (Table 2). Refugees had statistically significant higher scores (mean $\mathrm{dmft} / \mathrm{DMFT}$ score $5.80 \pm 4.24$ ) than immigrants, (mean dmft/DMFT score was $3.52 \pm 3.78$ $(p<0.001)$ (Table 2) However, only the filled teeth scores differed significantly between the two groups, with a mean score of $0.48 \pm 1.52$ for the immigrants and $1.55 \pm 2.36$ 
Table 1 Demographic characteristics of recent immigrants and refugee participant children

\begin{tabular}{lllll}
\hline & Immigrants $(n=44)$ & Refugees $(n=89)$ & Total $(n=133)$ & $p$ value \\
\hline $\begin{array}{l}\text { Sex distribution } \\
\text { Males }\end{array}$ & $22(50 \%)$ & $53(59.6 \%)$ & $75(56.4 \%)$ & \\
$\quad$ Females & $22(50 \%)$ & $36(40.4 \%)$ & $58(43.6 \%)$ & \\
Age & & & \\
Mean & $8.63 \pm 2.96$ & $9.22 \pm 2.89$ & $9.02 \pm 2.91$ & $0.28^{*}$ \\
Maximum & 14.51 & 15.17 & 15.17 & \\
Minimum & 3.18 & 3.22 & 3.18 & $0.35^{* *}$ \\
3-6 years & $11(25 \%)$ & $14(15.7 \%)$ & $25(18.8 \%)$ & $102(76.7 \%)$ \\
$>6-14$ years old & $32(72.5 \%)$ & $70(78.7 \%)$ & $6(4.5 \%)$ & \\
$>14-16$ years old & $1(2.3 \%)$ & $5(5.6 \%)$ & & \\
\hline
\end{tabular}

* Independent samples $t$ test

** Fisher's exact test
Table 2 Oral Hygiene Index and DMFT Score in recent immigrants and refugee children

\begin{tabular}{llll}
\hline & Immigrants & Refugees & $p$ value \\
\hline OHIS scores (mean) & $1.51 \pm 0.88$ & $1.57 \pm 0.99$ & $0.86^{*}$ \\
Maximum & 3.17 & 6 & \\
Minimum & 0 & 0 & \\
DMFT score (mean) & $3.52 \pm 3.78$ & $5.80 \pm 4.24$ & \\
Maximum & 12 & 16 & \\
Minimum & 0 & 0 & $<\mathbf{0 . 0 0 1} *$ \\
Median & 2 & 5 & \\
DMFT score categories & & & \\
DMFT score $=0-3$ & $26(59.1 \%)$ & $32(36 \%)$ & $\mathbf{0 . 0 4 * *}$ \\
DMFT score $=4-8$ & $11(25 \%)$ & $32(36 \%)$ & \\
DMFT score $\geq 9$ & $7(15.9 \%)$ & $25(28 \%)$ & \\
\hline
\end{tabular}

Statistically significant values $(p<0.05)$ are given in bold

* Mann-Whitney U test

** Fisher's exact test

for refugees $(p<0.001)$ (Table 3). Inflammation scores and the requirement for other treatment needs did not differ significantly approximately $70 \%$ of our sample had visible signs of gingival inflammation. The majority of children required a restorative treatment, scaling and plaque control instructions (Table 4).

\section{Risk Determinants}

Among the potential predictor variables analyzed, age of the parent, parents' views about brushing teeth after meals, oral hygiene status of the child's mouth, presence of inflammation in the child's mouth and place of origin (for analysis, the countries were divided into three broad categories-Indian subcontinent, other parts of Asia, and the rest of the world) were found to be statistically significant in the univariate analysis ( $p$ value $=0.2$ ).
Backward selection of the variables was used to build the model wherein, all the statistically significant predictor variables (as determined by univariate analysis) were included and modeled repeatedly while eliminating non-significant variables at $p$ value 0.05 until all the variables included in the model were statistically significant. In multivariate analysis, country of origin, and gingival inflammation were found to be significant determinants for caries. The odds of the presence of at least one carious tooth in participants who came from other parts of Asia, excluding the Indian subcontinent (most of whom were refugees), were 3.54 (95\% CI 1.10-11.37) times more than participants from the category-rest of the world. Similarly, the odds of the presence of at least one carious tooth were 2.31 (95\% CI 0.94-5.66) times more in the presence of general inflammation (Table 5).

\section{Survey Questionnaire}

The questionnaire (Table 6) was completed by 28 immigrant ( 22 females and 6 males) and 58 refugee ( 34 female and 24 male) parents/guardians of the children. The mean age of the immigrant participants was $38.07 \pm 5.21$ years (range 29-48 years), and the mean age of refugee participants was $36.14 \pm 8.02$ years (range 20-57 years). The majority of immigrants arrived from Pakistan and refugees came from Burma.

A significantly higher number of immigrant participants were aware of dental plaque, the protective effects of fluoride on teeth and causes of tooth decay. A significantly higher number of immigrants also reported that a dentist had shown them a tooth-brushing technique and were proficient in English. More than one-third of refugee participants had never been to a dentist for any preventive or restorative services. 
Table 3 Decayed, missing, filled teeth in a group of recent immigrants and refugee children in Saskatchewan
Table 4 Other treatment needs in a group of recent immigrants and refugees in Saskatchewan
Table 5 Risk determinants in a group of recent immigrants and refugee children

\begin{tabular}{|c|c|c|c|}
\hline & Immigrants $(n=44)$ & Refugees $(n=89)$ & $p$ values \\
\hline \multicolumn{4}{|l|}{ No. of decayed teeth } \\
\hline Mean & $2.41 \pm 3.44$ & $3.01 \pm 3.49$ & \\
\hline Maximum & 12 & 13 & \\
\hline Minimum & 0 & 0 & \\
\hline Median & 1 & 2 & $0.22 *$ \\
\hline \multicolumn{4}{|l|}{ No. of Subjects with } \\
\hline $0-3$ decayed teeth & $33(75 \%)$ & $60(67.4 \%)$ & $0.74 * *$ \\
\hline 4-8 decayed teeth & $7(15.9 \%)$ & $19(21.3 \%)$ & \\
\hline$\geq 9$ decayed teeth & $4(9.1 \%)$ & $10(11.2 \%)$ & \\
\hline \multicolumn{4}{|l|}{ No. of missing teeth } \\
\hline Mean & $0.64 \pm 1.12$ & $1.25 \pm 2.20$ & \\
\hline Maximum & 4 & 12 & \\
\hline Minimum & 0 & 0 & \\
\hline Median & 0 & 0 & $0.08 *$ \\
\hline \multicolumn{4}{|l|}{ No. of subjects with } \\
\hline $0-3$ missing teeth & $42(95.5 \%)$ & $83(93.3 \%)$ & $0.70 * *$ \\
\hline 4-8 missing teeth & $2(4.5 \%)$ & $3(3.4 \%)$ & \\
\hline$\geq 9$ missing teeth & $0(0 \%)$ & $3(3.4 \%)$ & \\
\hline \multicolumn{4}{|l|}{ No. of filled teeth } \\
\hline Mean & $0.48 \pm 1.52$ & $1.55 \pm 2.36$ & \\
\hline Maximum & 8 & 9 & \\
\hline Minimum & 0 & 0 & \\
\hline Median & 0 & 0 & $<0.001 *$ \\
\hline \multicolumn{4}{|l|}{ No. of subjects with } \\
\hline $0-3$ filled teeth & $41(93.2 \%)$ & $71(79.8 \%)$ & $0.16^{* *}$ \\
\hline $4-8$ filled teeth & $3(6.8 \%)$ & $16(18 \%)$ & \\
\hline$\geq 9$ filled teeth & $0(0 \%)$ & $2(2.2 \%)$ & \\
\hline
\end{tabular}

Statistically significant value $(p<0.05)$ is given in bold

* Mann-Whitney U test

** Fisher's exact test

\begin{tabular}{lccc}
\hline Need & Immigrants & Refugees & $p$ value \\
\hline Urgent treatment for pain and infection & $3(6.8 \%)$ & $4(4.5 \%)$ & $0.68^{*}$ \\
Extraction or surgery & $3(6.8 \%)$ & $10(11.2 \%)$ & $0.54^{*}$ \\
Restorations & $24(54.5 \%)$ & $51(57.3 \%)$ & $0.76^{* *}$ \\
Plaque control instruction & $42(95.5 \%)$ & $81(91 \%)$ & $0.50^{*}$ \\
Scaling and root planing & $20(45.5 \%)$ & $41(46.1 \%)$ & $0.95^{* *}$ \\
Orthodontic treatment & $15(34.1 \%)$ & $35(39.3 \%)$ & $0.56^{* *}$ \\
\hline
\end{tabular}

* Fisher's exact test

** Pearson's Chi square test

\begin{tabular}{lccc}
\hline Parameter & Estimate (adjusted model) & Odd's ratio & $95 \%$ CI \\
\hline Intercept & -1.56 & & \\
Origin & 1.26 & 3.54 & $1.10-11.37$ \\
Other Asia & & & \\
General inflammation & 0.84 & 2.31 & $0.94-5.66$ \\
Oral Hygiene Index & 1.00 & 2.72 & $0.59-12.59$
\end{tabular}

Results of logistic regression analyses 
Table 6 Selected questions relating to self-reported knowledge, behavior and attitudes towards oral health

\begin{tabular}{|c|c|c|c|}
\hline & Immigrant adults $(n=28)$ & Refugee adults $(n=58)$ & $p$ value \\
\hline \multicolumn{4}{|l|}{ Age of the participant } \\
\hline Mean & $38.07 \pm 5.21$ & $36.14 \pm 8.02$ & $0.09 *$ \\
\hline Minimum & 29 & 20 & \\
\hline Maximum & 48 & 57 & \\
\hline \multicolumn{4}{|l|}{ Sex of the participant } \\
\hline Male & $6(21 \%)$ & $24(41 \%)$ & $0.07 * *$ \\
\hline Female & $22(79 \%)$ & $34(59 \%)$ & \\
\hline \multicolumn{4}{|l|}{ Should you clean your teeth after meals? } \\
\hline Yes & $25(89 \%)$ & $36(62 \%)$ & $0.009 * *$ \\
\hline No & $3(11 \%)$ & $22(38 \%)$ & \\
\hline \multicolumn{4}{|l|}{ Are sweets most harmful for your teeth? } \\
\hline Yes & $26(93 \%)$ & $54(93 \%)$ & $1.00^{\dagger}$ \\
\hline No & $2(7 \%)$ & $4(7 \%)$ & \\
\hline What causes a tooth to decay? & & & $\mathbf{0 . 0 0 2}{ }^{\dagger}$ \\
\hline Gave the correct answer & $22(79 \%)$ & $29(50 \%)$ & \\
\hline Gave wrong answer & $3(11 \%)$ & $2(3 \%)$ & \\
\hline Do not know & $3(11 \%)$ Std res $(-2.2)$ & $27(47 \%)$ & \\
\hline Have you heard of Dental Plaque? & & & $\mathbf{0 . 0 0 3}^{\dagger}$ \\
\hline Yes & $18(64 \%)$ Std res $=2.1$ & $16(28 \%)$ & \\
\hline No & $8(29 \%)$ & $25(43 \%)$ & \\
\hline Do not know & $2(7 \%)$ & $17(29 \%)$ & \\
\hline What is dental floss? & & & $0.25^{\dagger}$ \\
\hline Correct explanation & $17(61 \%)$ & $26(45 \%)$ & \\
\hline Wrong explanation & $1(4 \%)$ & $1(2 \%)$ & \\
\hline Do not know & $10(36 \%)$ & $31(53 \%)$ & \\
\hline Does fluoride make your teeth strong? & & & $<0.001^{\dagger}$ \\
\hline Yes & $21(75 \%$ of 28$)$ Std res $=2.7$ & $15(26 \%$ of 58$)$ & \\
\hline No & $1(4 \%$ of 28$)$ & $4(7 \%$ of 58$)$ & \\
\hline \multicolumn{4}{|l|}{ Barriers } \\
\hline Lack of money & $14(50 \%)$ & $32(55 \%)$ & $0.76^{\dagger}$ \\
\hline Lack of insurance & $14(50 \%)$ & $24(41 \%)$ & $0.76^{\dagger}$ \\
\hline Fear of pain & $5(18 \%)$ & $14(24 \%)$ & $0.72^{\dagger}$ \\
\hline English language & $2(7 \%)$ & $33(57 \%)$ & $<0.0001^{\dagger}$ \\
\hline Work schedule conflict & $4(14 \%)$ & $11(19 \%)$ & $0.84^{\dagger}$ \\
\hline Lack of transportation & $3(11 \%)$ & $13(22 \%)$ & $0.41^{\dagger}$ \\
\hline
\end{tabular}

Statistically significant values $(p<0.05)$ are given in bold

* Independent samples $t$ test

** Pearson's Chi square test

$\dagger$ Fisher's exact test

\section{Discussion}

To our knowledge, this study is the first to document the oral health status and needs of this population in Saskatchewan, Canada. The mean dmft/DMFT scores were $5.80 \pm 4.24$ and $3.52 \pm 3.78$ for the refugees and the immigrants respectively, which is considerably higher than the scores of children (0.49), aged 6-11 years born in
Canada [21]. Dental caries was found in $15.1 \%$ of the immigrant teenagers, but only in $3.8 \%$ of children born in Canada [22]. Further, a study conducted in Nova Scotia, Canada reported a large proportion of Bhutanese immigrants and refugees had untreated caries and gingivitis [23].

Data from the Saskatchewan Dental Health Screening Program 2008-09 suggest that among 8835 grade 7 students (age 12) living in the province, the average DMFT 
was only 0.80 [24]. Within the same age group, $11.4 \%$ of these students did not need dental treatment, while $66.2 \%$ of them were caries free in their permanent dentition. Similar results were reported in a much younger cohort of 9079 grade 1 students aged 6 (dmft/DMFT was 3.14). The Saskatchewan Dental Health Screening Program, 2008-2009 report also indicated that $41.5 \%$ of the same age group of grade 1 students were caries-free, and $27.1 \%$ of them did not require any restorative dental therapy.

Findings from our study and others carried out in Canada suggest that the dmft/DMFT scores for recent immigrants and refugees are higher than the national norm and hence do not meet the Canadian Oral Health Strategy Guidelines (2010) for children in grade one. Maserejian et al. [25] compared the caries experience of children of immigrants to the children of US-born caregivers at enrollment and new caries increments during the 5-year New England Children's Amalgam Trial. As expected, at baseline, the children of immigrants had more carious lesions than residents. They also reported that Immigrant status and language preference were not associated with 5 -year caries increments.

The feedback from our questionnaire revealed that, in general, immigrants and refugees have other priorities and concerns such as the stress associated with adapting to a new culture, learning English as a second language, issues with transportation, finance, and finding schools for children to deal with before they can consider their children's oral health needs [26]. Even if they do desire to seek dental care, most find the cost of regular treatment at a private dental office, prohibitive, especially since most newcomers do not have dental insurance or the financial means to meet the cost. Similar results were reported in a group of 48 mothers of 3-5 year-old children from selected African communities in Alberta, Canada [27]. These immigrant mothers had been living in Canada for 5 years or less. Access barriers were associated with parental knowledge of preventive services, English skills, and external constraints concerned dental insurance, social support, time, and transportation. Inadequate dental coverage appears to be associated with low income as evidenced by a recent national survey with a group of Canadian adults [28]. This survey reported that only a small percentage $(19.3 \%)$ of the lowest income group had private dental insurance compared with $80.5 \%$ of the highest income group. Such barriers may impede regular visits to a dental office and negatively impact oral health outcomes in vulnerable population groups.

\section{Limitations of the Study}

Limitations of the study include the relatively small sample size and convenience sampling approach to data collection.
Therefore, our results may not be generalizable to all immigrant and refugee children. Another limitation is that we had a few families with more than one child enrolled in the study. This may have created biases in our results. However, since all families were similar in terms of their poor socioeconomic status, we do not expect a high level of bias in our results.

\section{Conclusion}

According to our study, refugee children have higher dmft/ DMFT scores than immigrant children; both of these groups are at a greater risk when compared to their native counterparts and this finding is consistent with studies done elsewhere [18]. These results can be used as a basis for more comprehensive assessments intended to plan publicly-funded oral health programs specifically targeting recent immigrants and refugees in the province of Saskatchewan. Focussed interventions can reduce the burden of disease on these populations and on funding agencies as well.

Acknowledgments We wish to thank the participants and clinical examiners, Ms. Karen Kuntz, A. Zerehgar and G. Lane. The study was supported by the Saskatchewan Health Research Foundation, and the Endowment Fund from the College of Dentistry, University of Saskatchewan and is part of the 'Healthy Immigrant Children Study'.

\section{Compliance with Ethical Standards}

This study complied with all ethical standards.

Conflict of interest The authors declare that they have no conflict of interest.

Ethical Standard This study was reviewed and approved by the University of Saskatchewan advisory board and complied with all ethics standards.

Human and Animal Rights All applicable international, national, and/or institutional guidelines for the care and use of human subjects were followed.

Informed Consent Informed consent was obtained from all individual participants/guardians included in the study.

Open Access This article is distributed under the terms of the Creative Commons Attribution 4.0 International License (http://crea tivecommons.org/licenses/by/4.0/), which permits unrestricted use, distribution, and reproduction in any medium, provided you give appropriate credit to the original author(s) and the source, provide a link to the Creative Commons license, and indicate if changes were made.

\section{References}

1. Gabriel PS, Morgan-Jonker C, Phung C M, Barrios R, Kaczorowski J. Refugees and health care-the need for data: 
understanding the health of government-assisted refugees in Canada through a prospective longitudinal cohort. Can J Public Health. 2011;102(4): 269-72. http://search.proquest.com.cyber. usask.ca/docview/884329223? accountid=14739

2. Rowan-Legg A, Canadian Paediatric Society, Community Paediatrics Committee. Oral health care for children-a call for action. Paediatr Child Health. 2013;18(1):37-50.

3. Hayes A, Azarpazhooh A, Dempster L, Ravaghi V, Quiñonez C. Time loss due to dental problems and treatment in the Canadian population: analysis of a nationwide cross-sectional survey. BMC Oral Health. 2013;13:17.

4. Melvin CS. A collaborative community-based oral care program for school-age children. Clin Nurse Spec. 2006;20(1):18-22.

5. Reza M, Amin M, Sgro A, Abdelaziz A, Ito D, Main P, Azarpazhooh A. Oral health status of immigrant and refugee children in North America: a scoping review. J Can Dent Assoc. 2016;82:g3.

6. Gatou T. Koletsi Kounari H, Mamai-Homata E: dental caries prevalence and treatment needs of 5- to 12-year-old children in relation to area-based income and immigrant background in Greece. Int Dent J. 2011;61(3):144-51. doi:10.1111/j.1875-595X. 2011.00031.x.

7. Lee J. Comparison of the dental health of Toronto's ethnic groups. Can J Community Dent. 1987;2:8-12.

8. Woodward GL, Leake JL. Risk markers for new dental decay in eight-year-old North York children. Can J Community Dent. 1995;10:7-13.

9. Abramson A, Heimann GA. A comparison of dental disease between Windsor Essex county children and recent immigrant children. Can J Community Dent. 1997;12:22-5.

10. Locker D, Clarke M, Murray H. Oral health status of Canadian born and immigrant adolescents in North York, Ontario. Community Dent Oral Epidemiol. 1998;26:177-81.

11. Clark M, Locker D, Murray H, Payne B. The oral health of disadvantaged adolescents in North York, Ontario, Canada. Can J Public Health. 1996;87:261-3.

12. Harrison R, Wong T, Ewan C, Contreras B, Phung Y. Feeding practices and dental caries in an urban Canadian population of Vietnamese preschool children. ASDC J Dent Child. 1997;64:112-27.

13. Guay AH. Access to dental care. Solving the problem for underserved populations. J Am Dent Assoc. 2004;135:1599-605.

14. Okunseri C, Hodges JS, Born DO. Self-reported oral health perceptions of Somali adults in Minnesota: a pilot study. Int $\mathrm{J}$ Dent Hyg. 2008;6(2):114-8.
15. Amin MS. Utilization of dental services by children in low income families in Alberta. J Can Dent Assoc. 2014;80:e51.

16. Greene JC, Vermillion JK. The simplified oral hygiene index. J Am Dent Assoc. 1964;68:7-13.

17. Peterson PE, Aleksejuniene J, Christensen LB, Eriksen HN, Kalo I. Oral health behavior and attitudes of adults in Lithuania. Acta Odontol Scand. 2000;58:243-8.

18. Stenburg P, Hakansson J, Akerman S. Attitudes to dental health and care among 20 to 25 -year-old Swedes: results from a questionnaire. Acta Odontol Scand. 2000;58:102-6.

19. Chhabra N, Chhabra A. Parental knowledge, attitudes and cultural beliefs regarding oral health and dental care of preschool children in an Indian population: a quantitative study. Eur Arch Paediatr Dent. 2012;13(2):76-82.

20. Al-Omiri MK, Jor Board, Al-Wahadni AM, Saeed KN. Oral health attitudes, knowledge, and behavior among school children in North Jordan. J Dent Educ. 2006;70(2):179-87.

21. Health Canada. Summary report on the findings of the oral health component of the Canadian Health Measures Survey 2007-2009. 2010. p. 4. www.fptdwg.ca/English/e-documents.html

22. Locker D, Clarke M, Murray H. Oral health status of Canadianborn and immigrant adolescents in North York, Ontario. Commun Dent Oral Epidemiol. 1998;26:177-81.

23. Ghiabi E, Matthews DC, Brillant MS. The oral health status of recent immigrants and refugees in Nova Scotia, Canada. J Immigr Minor Health. 2014;16:95-101.

24. Pilly VK. Saskatchewan dental health screening program, 2008-2009 report, produced by the Dental Health Promotion Working Group of Saskatchewan. 2010.

25. Maserejian NN, Trachtenberg F, Hayes C, Tavares M. Oral health disparities in children of immigrants: dental caries experience at enrollment and during follow-up in the New England Children's Amalgam Trial. J Pub Health Dent. 2008;68(1):14-21.

26. http://www.cic.gc.ca/english/resources/publications/rpp/20152016/

27. Amin M, Perez A. Is the wait-for-patient-to-come approach suitable for African newcomers to Alberta, Canada? Commun Dent Oral Epidemiol. 2012;40(6):523-31.

28. Locker D, Maggirias J, Quinonez C. Income, dental insurance coverage and financial barriers to dental care among Canadian adults. J Public Health Dent. 2011;71:327-34. 